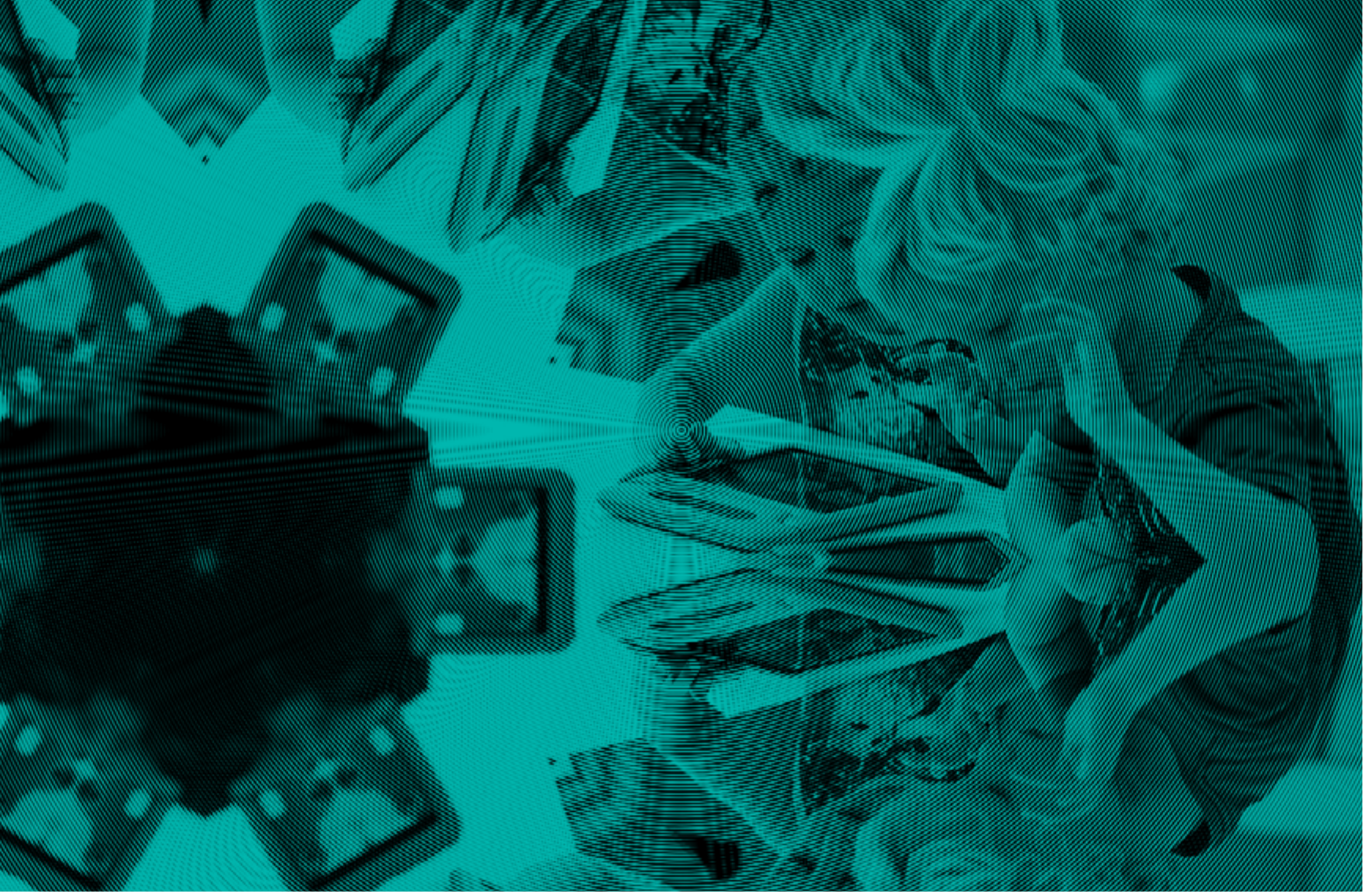

\title{
Parchemos: artes, política y comunicación en la escuela
}

Parchemos: arts, politics and communication at school

Parchemos: artes, política e comunicação na escola

Ricardo Alfonso Soler Rubio Guillermo Alfonso Viasús Quintero 
Ricardo Alfonso Soler Rubio 1 Guillermo Alfonso Viasús Quintero 2
1. Sociólogo, Universidad Nacional de Colombia; correo electrónico: rasolerr@unal.edu.co

2. Estudiante de Lingüística, Universidad Nacional de Colombia; correo electrónico: gaviasusq@unal.edu.co
Fecha de recepción: 18 de abril de 2016 / Fecha de aceptación: 16 de septiembre de 2016

\section{Resumen}

Este artículo presenta los resultados del proyecto de investigación "Parchemos: Creando paz desde la comunicación en la escuela y el barrio", desarrollado en el marco de la Beca de InvestigaciónAcción en Cultura Democrática Guillermo Hoyos Vásquez, en su versión 2015. El proyecto buscó fortalecer las prácticas ciudadanas en el contexto escolar del grado noveno de la Institución Educativa Distrital Eduardo Umaña Luna, para favorecer la construcción de paz y cultura democrática desde la comunicación como apuesta política, potenciando estos procesos desde las artes musicales y visuales.

Palabras clave: Educación para la paz, cultura democrática, comunicación, cultura escolar.

\section{Summary}

This article presents the results of the research project called "Parchemos: creando paz desde la comunicación en la escuela y en el barrio" framed in the fellowship of Action Research in Democratic Culture Guillermo Hoyos Vásquez, on its 2015 version. The project aimed to strengthen the civic practices at school context of the ninth grade from the District Educative Institution Eduardo Umaña Luna, in search of peace construction and democratic culture using communication as a political stake, improving these processes from musical and visual arts.

Keywords: Peace Education, Democratic Culture, Communication, School Culture.

\section{Resumo}

Este artigo apresenta os resultados do projeto de pesquisa "Parchemos: creando paz desde la comunicación en la escuela y en el barrio" desenvolvido no âmbito da Bolsa de Pesquisa de investigação-ação em Cultura Democrática Guillermo Hoyos Vásquez, na sua versão 2015. O projeto procurou fortalecer as práticas cidadãs no contexto escolar do nono grado da Instituição Educativa Distrital Eduardo Umaña Luna, em prol da construção da paz e de cultura democrática desde a comunicação como aposta política, potencializando estes processos desde as artes musicais e visuais.

Palavras chave: Educação para a paz, Cultura democrática, Comunicação, Cultura escolar 


\section{Introducción}

En el contexto colombiano, el campo educativo se ha venido consolidando como un objeto constante de intervenciones e investigaciones por parte de distintos agentes nacionales e internacionales, en donde transitan o incluso se imponen discursos y acciones específicas sobre los sujetos implicados en el proceso educativo: proyectos gubernamentales para hacer más competentes y efica$\operatorname{ces}^{3}$ a la administración educativa y al personal docente; jornadas ampliadas; contratación de corporaciones para mejorar el desempeño en las pruebas estandarizadas a nivel nacional e internacional; $\mathrm{e}$ incluso maximizar económicamente los recursos para abarcar una mayor cantidad de población con el fin de mejorar indicadores.

Sin embargo, la posibilidad de incidir en la cotidianidad de los procesos educativos, reconociendo realmente a los niños, niñas y jóvenes como sujetos (no solamente de derecho, sino en plena capacidad de construir, crear y compartir sentidos de vida), se ve reducida a simples proyectos de corta duración, o a la voluntad pedagógica y política de escasos docentes aún con vitalidad para generar procesos alternativos de formación que no se reduzcan a mejorar el desempeño de sus estudiantes en las pruebas estandarizadas, sino que procuren generar espacios de creación de sentido o de mentalidades críticas.

En este sentido, es importante la posibilidad de compartir y de visibilizar algunas voces desde perspectivas no tan nuevas, para posicionar al interior, no solo de los centros académicos, sino de la reflexión docente y el debate público, la necesidad de seguir replanteando los procesos educativos, pero reconociendo a estos sujetos históricamente infantilizados como voces y experiencias capaces de dar cuenta del estado actual de la institución escolar: su crisis como ente productor de saberes, y de sujetos "mayores de edad", que sigue imponiéndose como dispositivo disciplinario (Sáenz, 2010), conduciendo sistemáticamente las subjetividades hacia la reproducción de un orden macro social cargado de prejuicios y con poca consciencia de la actual situación económica y ambiental, y a la imposibilidad de pensar proyectos de vida que produzcan bienestar colectivo en los territorios que habitamos.

3 En el Decreto 1055 de 2011 del MEN, Artículo 6, se hacen explícitas las estrategias para promover el reconocimiento a la gestión, las cuales se fundamentan en aumentar los niveles de permanencia y calidad. El indicador de calidad: "Se calcula como la relación entre el número de estudiantes con mejores resultados a partir del percentil 75 en los resultados de español y matemáticas en las pruebas SABER PRO del año n, sobre el número de estudiantes que presentan las pruebas SABER PRO del año n".
El proyecto que aquí presentamos tuvo como propósito fortalecer las prácticas ciudadanas en el contexto local, pretendiendo mejorar en el entorno escolar las posibilidades de construcción de paz y de cultura democrática, desde la comunicación como apuesta política que permite manifestar el sentir y pensar de los estudiantes, potenciando estos procesos desde las artes musicales y visuales.

El proyecto de investigación fue financiado en el marco de la Beca de Investigación-Acción en Cultura Democrática Guillermo Hoyos Vásquez, promovida por la Secretaría Distrital de Cultura, Recreación y Deporte en conjunto con el Instituto de Estudios Sociales y Culturales "Pensar", de la Pontificia Universidad Javeriana, y el Instituto Goethe de Bogotá. El Colegio Eduardo Umaña Luna IED se encuentra ubicado en el barrio Dindalito (UPZ 82 -Patio Bonito) de la localidad de Kennedy.

El Colegio abarca los niveles educativos desde preescolar hasta educación media, con la posibilidad para el estudiantado de últimos años de recibir formación técnica en convenio con el SENA. La población estudiantil proviene en su mayoría de las UPZ aledañas a la institución como Corabastos, Britalia, Tintal, entre otras, y está compuesta por poblaciones de diversas trayectorias y orígenes geográficos y culturales. La localidad de Kennedy, en particular las UPZ 80 y 82, ha sido contemplada y estigmatizada como zona de alto riesgo y de intervención prioritaria, en procesos como la "Estrategia Integral de priorización y focalización 75/100 de Bogotá D.C.” (Alcaldía de Bogotá, 2013)

El colegio se ve influenciado por las dinámicas poblacionales, sociales, económicas y políticas propias de su contexto. De acuerdo con la SED y el Hospital de Kennedy (2010), en el territorio de Kennedy se cuentan cerca de 48.760 jóvenes de diferentes edades que conviven con problemáticas estructurales de la ciudad como la inseguridad, casos de violencia (física, emocional, sexual, agresión familiar, de género), tráfico de sustancias psicoactivas, amenazas de "limpieza social" por parte de bandas paramilitares, que estigmatizan a los jóvenes y a sus formas de vida, llegando incluso a causar varias muertes en la localidad, y casos de maltrato infantil y violencia contra las mujeres.

A pesar de que estas situaciones afectan a la ciudad en general, el diagnóstico deja claro el hecho de que la población de infancia y juventud es una de las más afectadas en la UPZ de Patio Bonito. El documento también contempla otros problemas relacionados con lo vulnerables que pueden ser los procesos de constitución de las identidades juveniles, debido a la influencia de grupos como barras bravas y "tribus urbanas", hecho que: 
Puede considerarse a la vez un mecanismo de respuesta a dificultades o situaciones conflictivas, donde la violencia es un patrón de conducta cotidiano en la comunidad. Si bien algunos jóvenes construyen su identidad dentro de confrontaciones ideológicas, asimetrías de poder, condiciones de pobreza o incomprensión, presentes al interior de familias o diversos ámbitos de la vida, otros promueven la organización y redes juveniles como mecanismo para la superación de sus necesidades y problemáticas (SED y Hospital de Kennedy, 2010, p. 140).

Así, la población joven del sector es estigmatizada por la población adulta, que desconoce y desvaloriza sus prácticas sociales y manifestaciones culturales, desencadenando problemas en red, ya que ellas tienden a ser reprimidas (por ejemplo, el grafiti) y anuladas en el contexto del territorio, impidiendo su reconocimiento como expresiones de interlocutores válidos en las discusiones y propuestas de transformación social local:

Si bien es cierto algunos jóvenes construyen su identidad en el marco de confrontaciones ideológicas, y relaciones de poder, la consolidación de parches y redes sociales con intereses comunes, les ha permitido encontrar una forma de equilibrio que en algunos casos favorece el desarrollo del territorio (SED y Hospital de Kennedy, 2010, p. 135).

\section{Metodología}

El análisis aquí presentado corresponde a una investigación cualitativa enmarcada en un diseño de etnografía educativa (Goetz y Lecompte, 1998), realizado en cuatro etapas: planeación, trabajo en campo, recolección de datos y análisis. El trabajo en campo consistió en el desarrollo de una serie de talleres temáticos dentro y fuera el aula con 3 grupos de grado noveno, de 2 jornadas escolares de la IED Eduardo Umaña Luna (EUL), contando cada curso con un promedio de 40 estudiantes. Estos talleres teóricos y prácticos generaron espacios participativos y de reflexión en torno a los temas que se buscaba problematizar: identidad, género, medios de comunicación, paz/conflicto, comunicación, democracia y lo político y la otredad; espacios en los que los/as estudiantes pudieron expresar a través de la música, el dibujo y el grafiti sus reflexiones personales y colectivas.

Dentro de las estrategias de recolección de la información se contemplaron posibilidades como la observación participante y no participante, entrevistas con las/os estudiantes y la realización periódica de grupos focales. Adicional a este proceso, los investigadores se preocuparon por extender una mirada etnográfica sobre el espacio del aula y las relaciones, tensiones y colaboraciones entre estudiantes y entre estudiantes y talleristas, complementándola con la información entregada por los/as estudiantes a través de dibujos, mapas y escritos cortos.

El proyecto tuvo una duración total de 4 meses, en los que se contó con la participación de una artista plástica, un músico percusionista y los miembros del grupo de investigación, dos sociólogos egresados y uno en formación, un estudiante de lingüística y una estudiante de Licenciatura en Educación Básica con énfasis en Ciencias Sociales.

\section{Resultados}

La reflexión guiada en los talleres de sensibilización buscó que las y los estudiantes no solo se acercaran a aspectos que buscaban complejizar la mirada sobre los actos comunicativos y las implicaciones éticas, políticas, históricas, individuales, emocionales y colectivas que éstos tenían en sus cotidianidades; sino que también tuvieran la posibilidad de participar de procesos de creación, reflexión y diálogo a partir del arte, como un espacio no solamente estético, sino dialógico y esencialmente comunicativo.

Con ello se buscaba promover en ellos y ellas una resignificación de sus prácticas comunicativas y proponer otras nuevas, entendiéndolas como sustento para la producción y reproducción de relaciones sociales y culturales. Los talleres en sí mismos tenían la intención de que durante el proceso los estudiantes se concienciaran de las prácticas y discursos culturalmente sedimentados y reproducidos en su colegio, y de cómo ellos y ellas podían incidir en esos discursos para controvertirlos y transformarlos.

Ejemplo de lo anterior fue el trabajo sobre los temas de identidad y género, que tuvo como sustento la idea de que la identidad no es un constructo estático, sino una construcción permanente que cambia con el tiempo (Hall, 2010) y que tiene la potencia de producir y reproducir estereotipos sociales sobre la alteridad étnica, de género, racial, etc. Las temáticas se abordaron desde una perspectiva de lo político como una acción personal que tiene incidencia en el entorno, desde los medios de comunicación como productores de discursos hegemónicos que circulan diariamente en nuestra sociedad, y desde lo conflictivo del encuentro de identidades diferentes en espacios de interacción en la ciudad.

Las preguntas y comentarios de los/as estudiantes, y las conexiones que hacían entre sus experiencias personales, el trabajo de los talleristas y los materiales de apoyo audiovisual de los talleres, les dieron herramientas para desnaturalizar las representaciones 
y las características que consideraban "esenciales" de las "otras" personas con quienes convivían diariamente en los espacios del colegio y del barrio.

Las reflexiones suscitadas por este tema se abordaron desde una propuesta de taller de apreciación musical que, a través de ejercicios básicos de escucha y de uso individual y colectivo de instrumentos musicales, buscó que los/as jóvenes se reconocieran como sujetos activos de su entorno, y que a través de las herramientas, que se les brindaron desde la didáctica musical, exploraran formas de comunicación que no necesariamente estuvieran mediadas por palabras. Se propuso que habilidades como la disposición a escuchar y a hacer silencio, o a apelar a la sensibilidad y al cuerpo para comunicar, construyen desde formas diferentes de comunicación (ya no exclusivamente uno a uno), al producir interdependencias directamente con el cuerpo propio, la otredad y con el entorno.

Lo anterior se relacionó con reflexiones sobre cómo sus formas de habitar y decidir sobre los espacios eran también maneras de hacer política y de participar activamente en lo que tiene que ver con la ciudadanía, entendiéndola como un elemento movilizador y transformador en sus relaciones de convivencia en el colegio y fuera de él, y no como la acción de ser mayor de edad y votar o tener cédula, como la entendían al inicio del proyecto. Todo esto, no en el marco de una sociedad ideal sin tensiones ni problemas, sino abordando constantemente los conflictos y desencuentros que se producen en el espacio de la ciudad.

El proyecto enlazó las reflexiones sobre identidad con los conflictos y las diferentes formas de violencia cotidiana a las que los/ as estudiantes están constantemente expuestos y que afectan sus vidas diarias (acoso callejero, racismo cotidiano, matoneo escolar, entre otros). Indagamos por las formas en que resolvían sus conflictos personales y grupales, lejos de las imágenes estereotipadas del conflicto como una problemática que se resuelve a través del diálogo, o como fenómeno opuesto a la paz, destacando el potencial del conflicto como espacio de transformación y de encuentro con la alteridad que puede tener posturas diferentes a las propias. En este sentido, las chicas y chicos reconocieron que el conflicto no necesariamente es la manifestación de algo que debe ser rechazado o negado, sino que significa una oportunidad de confrontación y cambio de posturas o condiciones.

A través de una discusión sobre la coyuntura actual del conflicto colombiano y los diálogos de paz, es importante rescatar algunos aportes de los alumnos, como la problematización de la paz en tanto concepto vacío que remite a una supuesta tranquilidad producida por la ausencia de conflictos, pero que desconoce la necesidad de ciertas condiciones, como mejoras en la calidad de vida de la gente y un control político sobre las élites históricamente

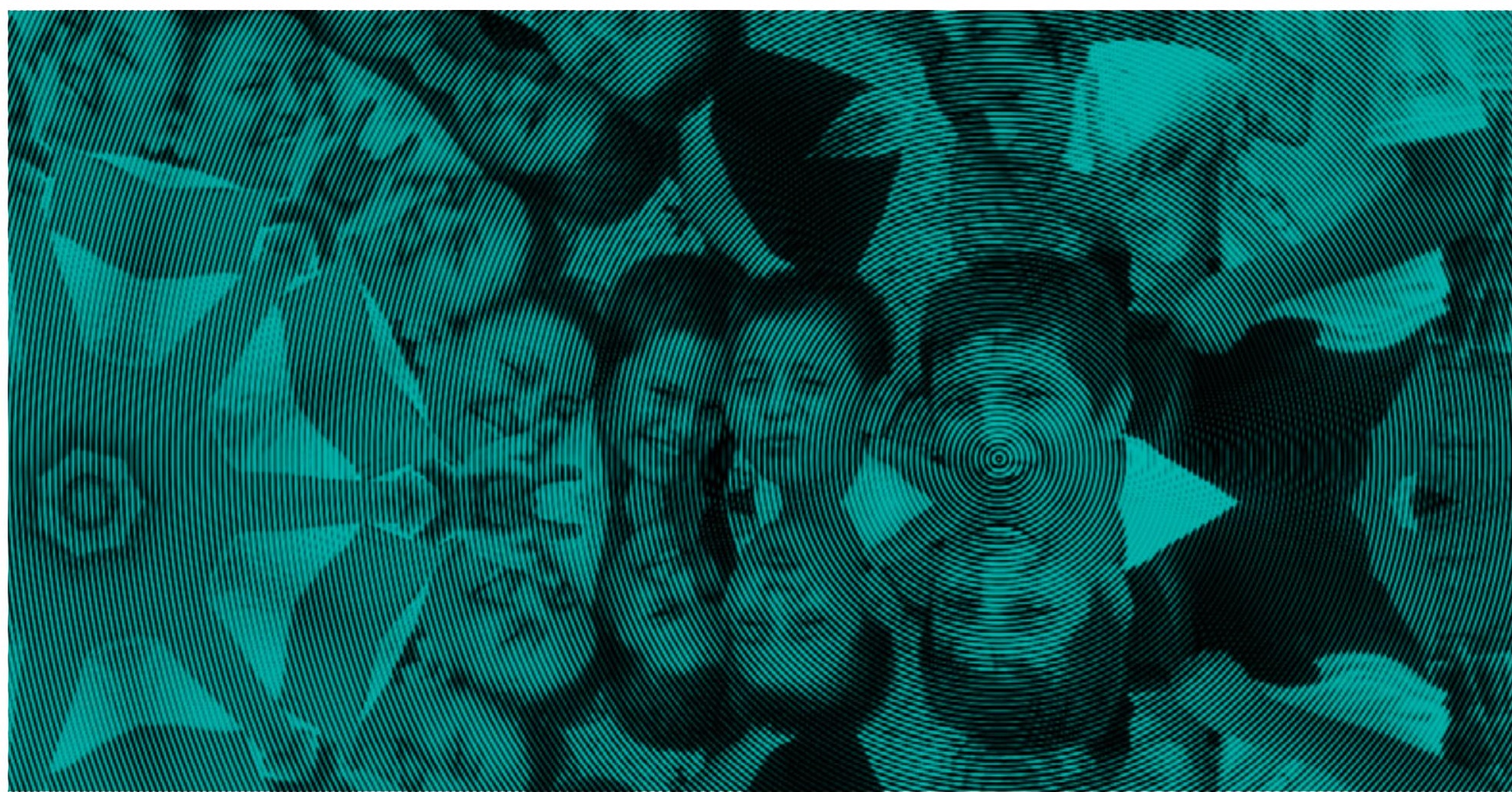


aficandas en el poder. Lo anterior también se analizó a nivel personal, dadas las experiencias que cada uno de los/as estudiantes tenían y las estrategias que usaban para transitar por situaciones de conflicto. Percibir al conflicto más allá de las valoraciones negativas sobre él, llevó a considerar que los disensos y las diferencias son constantes en las relaciones interpersonales.

En conjunto con los participantes se realizaron varias discusiones en torno a materiales audiovisuales que mostraban los discursos de los medios de comunicación, cuestionando constantemente que transmitir un mensaje fuera un proceso ideal, aséptico y racional, ya que esta percepción desconoce las dinámicas contextuales que modifican por completo la recepción y la producción de mensajes y significados. Se buscó que el estudiantado también dilucidara las intenciones detrás de los mensajes comunicados, que tenían una naturaleza fundamentalmente política, en la medida en que presentaban una representación de la realidad que promovía prácticas y prejuicios que llegaban a afectar la forma de conocer a la alteridad.

En este sentido, consideramos interesante reconocer que, en la actualidad, la escuela como institución de saber se encuentra en disputa con las nuevas formas de socialización y formación a las que se exponen los/as estudiantes, como los medios de comunicación (Reguillo Cruz, 2000, p. 7), debido a que la información aparentemente neutral que se presenta en distintos formatos, y de fácil acceso, genera nociones sobre una realidad que no necesariamente les atañe en la cotidianidad, y producen imágenes de lugares y culturas con las que no se tiene contacto directo; sin embargo el receptor se sujeta a ellas por la inmediatez de lo visual y lo narrado, percibiéndolas como una única verdad.

Trabajamos en la creación de un mural (instalado por el colegio en la sección de preescolar) que reflejaba los aprendizajes de los/ es estudiantes durante la investigación; participaron activamente en todo el proceso, que incluyó el dibujo y corte de plantillas, la preparación de la superficie y la pintura en aerosol del mural. Este ejercicio despertó su curiosidad y buena disposición, llevándoles a manifestar su agrado por el espacio para la elaboración práctica y creativa, pues les permitió expresarse libremente; criticaron que no tenían muchos espacios para actividades similares. También fue significativo el hecho de que fue posible re-significar prácticas artísticas como el grafiti y el muralismo, y sus aportes a la reflexión sobre la intervención del espacio público de la ciudad, convirtiéndose no solo en una forma de hacer arte, sino de comunicar y hacer visible la opinión personal.

Buscamos que el taller sirviera para mostrar que desde sus formas de relacionarse, percibirse y comunicarse con los sujetos de

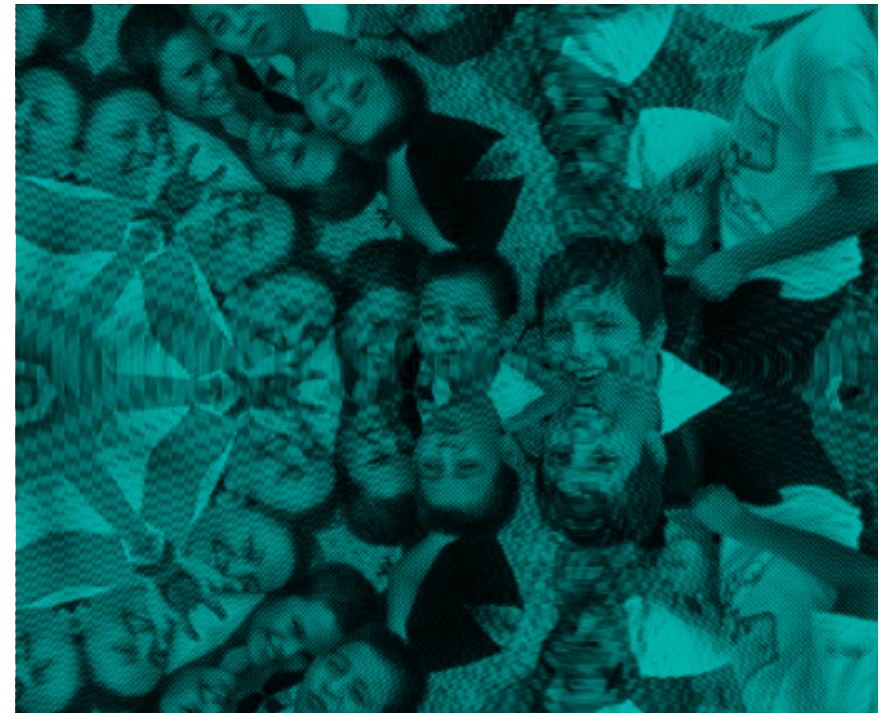

su cotidianidad, las/os estudiantes tenían un rol central en la construcción de ciudadanías capaces de proponer y generar cambios en sus entornos locales, replanteando y resignificando la idea de ciudadanía desde la acción comunicativa, lo cual pasa por la indagación de:

Las reglas explícitas y ocultas que regulan los comportamientos, las historias y los mitos que configuran y dan sentido a las tradiciones e identidades, así como a los valores y las expectativas que desde fuera presionan la vida de la escuela y del aula (Pérez-Gómez, 2005, p. 162).

Es en los puntos de encuentro entre dichas reglas y el conjunto de saberes y poderes que regulan al aula y a la escuela, donde tienen lugar las posibilidades de potenciar procesos que fomenten la transformación y la producción cultural, entendida como:

El uso creativo de los discursos, los significados, los materiales, las prácticas y los procesos de grupo, para explorar, comprender y ocupar creativamente posiciones particulares en los conjuntos de posibilidades materiales que, en general, se hallan disponibles (Willis, 1993).

El ámbito de la producción cultural (en este caso, el que se desarrolla en la escuela) siempre está abierto a la creación, pero también en tensión permanente con las manifestaciones anteriores de cultura y con la tendencia que tiene ésta de reproducirse. La visión resignificada de la constitución de las prácticas comunicativas como expresiones del lenguaje y de la cultura individual y colectiva, permite concebir formas amplias de producción de las posibilidades de la comunicación, las cuales pasan por diferentes tipos de narrativas como la escritura, la oralidad, el arte, lo audiovisual y lo pictórico, entre otras. 
En este sentido, pensar la comunicación como acto político, y de paso cuestionar a las y los estudiantes sobre los lenguajes usados tradicionalmente en los procesos educativos, posibilita trascender la escritura y la lectura en sus formas elementales, para abrirle campo a lenguajes menos cristalizantes de la realidad social y subjetiva, abriendo paso a la creatividad y a la ambigüedad de producción de sentidos y significados. Esta posibilidad de subjetivación, a través de nuevos lenguajes al interior del aula, implica entonces hacer un mayor esfuerzo para decodificar la información adquirida (tanto para estudiantes como para docentes), lo cual requiere de promover la empatía o la sensibilidad (sensorial, de investigar), y también potenciar la capacidad de construirse subjetivamente en relación con otredades, para poder consensuar significados, sentidos e intenciones en los actos educativos y comunicativos.

\section{Conclusiones}

Luego de un corto semestre donde compartimos con las y los estudiantes a través de varios talleres de sensibilización y artísticos, y donde intentamos establecer un precedente para posicionar el debate sobre cultura democrática a través de la comunicación, creemos que nuestras herramientas de investigación pueden quedarse cortas para exponer algunos indicadores fiables de transformaciones subjetivas o culturales de largo alcance, tanto de los y las estudiantes como de nosotros mismos, mucho más considerando

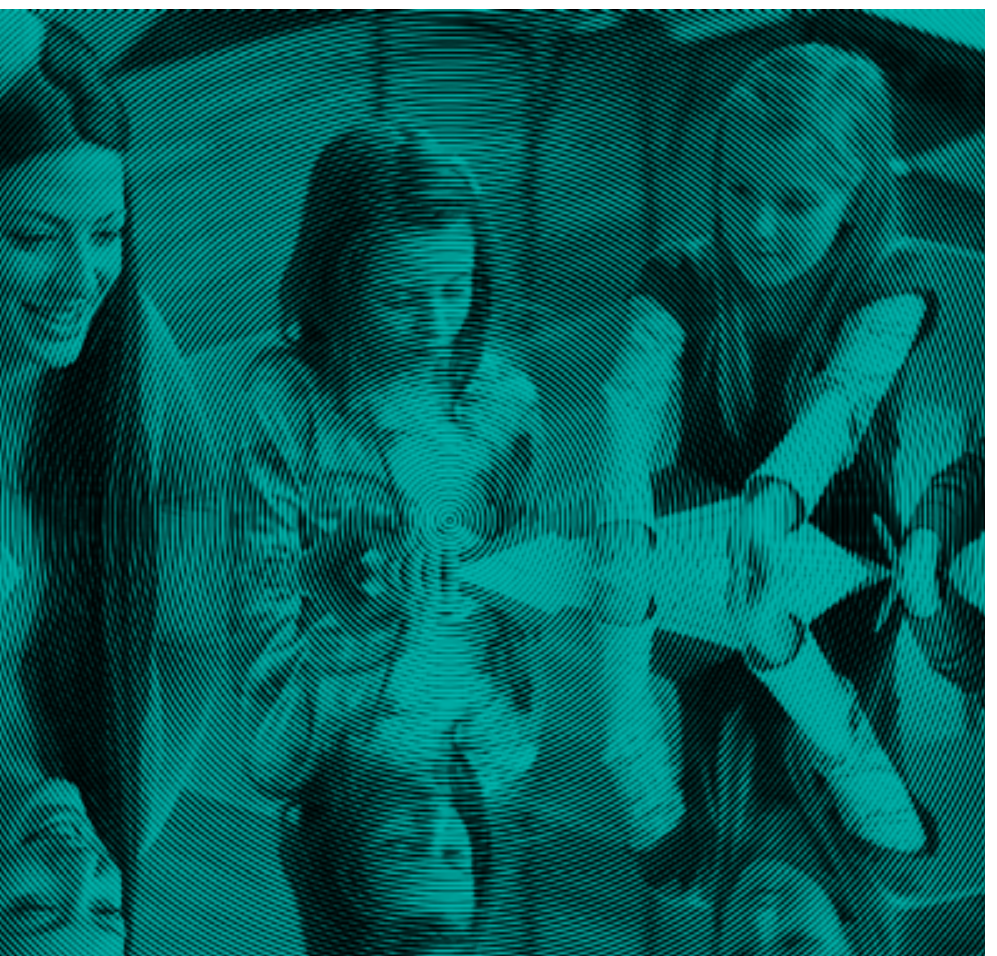

que intentábamos dar cuenta de un estado de cosas mientras buscábamos producir cambios en él; aún así tratamos de recoger aquí unos resultados que tienen más bien la forma de aprendizajes mutuos, pues reconocemos el carácter situado y limitado del proceso como la posibilidad de seguir desarrollando preguntas y acciones siempre inacabadas que movilicen nuevas posibilidades de acción, sentido y reflexión sobre la condición humana individual y colectiva.

Antes que nada, debemos decir que a partir de lo visto en el espacio escolar, los y las estudiantes vienen con unos referentes culturales, sedimentados histórica y biográficamente, que son constantemente actualizados, como se evidencia en el uso de ejercicios que buscan generar desplazamientos de las certezas o del "sentido común" en temas como la identidad de género, o en intentar construir colectivamente el término de política; estos referentes no solo permean fuertemente su habitus, sino que dan forma a sus propias identidades y definen sus formas de ser y de producir relacionamientos.

Así que cuando proponemos la tarea de producir cambios culturales a partir de una serie de actos alejados del programa curricular, sabemos que es un trabajo bastante limitado porque es preciso fomentar desde las instituciones escolares y académicas procesos sistemáticos de largo aliento, en donde se trasciendan de las visiones instrumentalistas y gerenciales de la educación pública como indicador de bienestar por su cobertura, y en donde se empiecen a pensar procesos situados con maestras y maestros interesados en fomentar procesos de construcción de subjetividades diferentes, sensibles y reflexivas de sí mismas y de su entorno, pero principalmente con ganas y posibilidades de crear alternativas para actuar, comunicarse, agenciar cambios y transformar su entorno, transformándose a sí mismas.

Llevar a cabo este proyecto se convirtió en un reto para cada uno de nosotros, pues nos enfrentamos a un escenario que, si bien no era nuevo, nos exigía estar en constante reflexión acerca de nuestro quehacer en el aula. Encontrarse en un espacio con jóvenes que durante la construcción de su historia han apelado a discursos y prácticas que no están precisamente relacionados con el ejercicio reflexivo de la cultura ciudadana, pues les resulta un discurso más impuesto que vinculado a sus realidades cotidianas, nos llevó a propiciar las confrontaciones respecto al modo en el que cada uno de ellos vivían y asumían su papel como ciudadanos.

Arriesgarnos a trabajar temas como el género o la producción de la identidad a partir de visiones dualistas cargadas de prejuicios, la vida personal como escenario político, entre otros, implicó 
un constante proceso de reflexión y de construcción colectiva de significados, además debimos re-pensarnos las prácticas pedagógicas, es decir, el cómo lograr que el aula se posicionara como lugar de producción de significados relevantes y contextualizados para los chicos y chicas, y ver que, al mismo tiempo, de allí surgiera la posibilidad de incentivar nuevas formas de reconocimiento de la otredad y de la diferencia. Este reto no se hubiese logrado sin la continua evaluación y reflexión sobre el desarrollo de cada uno de los talleres y de las metodologías utilizadas, que pretendían propiciar espacios reflexivos y creativos para cada uno de las y los estudiantes.

Consideramos que el proceso de confrontación vivido durante el diseño y la ejecución de los talleres logró poner sobre la mesa los discursos, prácticas y roles que estaban imbricados en el acervo cultural de los chicos y chicas, lo cual nos y les brindó herramientas para poner en duda el sistema simbólico de representaciones culturalmente sedimentado, no solo dejando la reflexión en términos discursivos, sino buscando trascenderla para empezar a generar prácticas comunicativas desde los sentires y pensares de los chicos y chicas sobre los espacios en que habitan, como sus barrios y la institución escolar.

Otro de los retos fue articular todo el andamiaje teórico/discursivo sobre el que se basó este proyecto, con las vivencias y prácticas cotidianas de cada uno de los/as estudiantes. Era claro que este proceso no podría llevarse a cabo siguiendo la lógica tradicional de las escuelas con clases magistrales y evaluaciones; por el contrario, nos enfocamos en que cada uno de los talleres de sensibilización tuviera como eje central la experiencia de los chicos y las chicas en su territorio, con su familia y en los diferentes espacios en los que se relacionan, para desde allí empezar a tejer los nuevos lazos entre teoría y práctica a partir de actividades, juegos y herramientas multimediales y textuales.

Hoy podemos ver reflejados nuestros esfuerzos en un pequeño cambio alrededor de la percepción y entendimiento de la serie de conceptos sobre los cuales centramos el trabajo de los talleres artísticos y de sensibilización, sobre todo en categorías fundamentales como la de democracia, la cual pasó, de ser una palabra sin significado inteligible para los estudiantes o con poca relevancia, a un término que no solo hacía referencia a su definición como la construcción colectiva de las decisiones, sino a uno que también tuvo la oportunidad de experimentarse en ejercicios como la creación del mural o de la muestra musical, y los trabajos grupales desarrollados a lo largo de todo el proyecto.
La política y lo político ${ }^{4}$ también se hicieron presentes en el proceso de re-significación de los estudiantes, quienes lograron superar su visión abstracta, instalada en su sentido común como la esfera pública, y rechazada por asociarse a los gobernantes "malos" o "corruptos", para empezar a considerar el hecho de que la política y lo político se juegan cada día en todas las esferas de la vida cotidiana y que, por ende, todos/as tenemos diferentes niveles de incidencia en ellas, cuestión fundamental en el camino hacia la construcción de una cultura escolar más democrática.

Por eso, conscientes de que podemos desanimarnos al encontrar frecuentemente la cara reproductora y conservadora de la máquina escolar y de caer en cualquier tipo de pesimismo estructuralista, que constantemente acecha el quehacer pedagógico, decidimos siempre partir de aquella premisa del pedagogo Paulo Freire de que en la educación no hay espacio para el pesimismo, sino que debe ser una práctica de y para la esperanza.

En este sentido, uno de los aprendizajes compartidos, y una potencia enorme que encontramos, es que en el contexto de una ciudad y de un país que se empiezan a cuestionar sobre la promoción de nuevas subjetividades pensando estratégicamente en culturas de paz, resulta enormemente interesante trabajar a través de "nuevos" lenguajes en los procesos educativos, como las artes en sus diversas modalidades, no solo usándolos como herramientas de transmisión de información, sino como productores de estéticas y subjetividades que vienen cargadas de sentido, de saberes, de trayectorias y mensajes que se omiten por el peso del legado histórico de la educación escolarizada como proceso instrumental e "iluminador".

El potencial de las artes como medios comunicativos inherentemente políticos y cargados de subjetividad, devela un debate importante para la pedagogía contemporánea, en donde se hace necesario pensar en procesos educativos constantes, que movilicen transformaciones subjetivas y debiliten el legado histórico-colonial de la escuela como proceso de imponer verdades, para dar paso a la ambivalencia de significados como camino para visibilizar otras historias y posibilidades de mundo, diversificando las voces y reconociendo a la otredad como elemento que permite ampliar saberes y experiencias.

Este proyecto fue una apuesta política que partió de reconocer que la escuela es y seguirá siendo un espacio preciso para llevar

4 Aludiendo a la distinción que hace la politóloga Chantal Mouffe, en donde la política se refiere a las instituciones de gobierno y lo político a las relaciones de poder existentes en los relacionamientos sociales. 
a cabo procesos pedagógicos reflexivos, pues creemos que solo haciendo sistemáticas las prácticas que movilicen diversos cuestionamientos en los estudiantes -pero a su vez motivándoles a comunicar sus percepciones e ideas-, es como se puede apuntar de manera efectiva y no impositiva a transformaciones, resignificaciones y producciones culturales que no solamente habiliten a las juventudes a participar de maneras creativas y novedosas en la sociedad civil, sino que permitan volver a enfocar el rol de la escuela como espacio para potenciar la vida en sus múltiples formas, en aras de desestabilizar su funcionamiento histórico como institución disciplinaria y normalizante, que reproduce órdenes racistas, sexistas y clasistas en las formas de relacionamiento con y en el mundo. 


\section{Bibliografía}

Alcaldía Mayor de Bogotá. (2013). Estrategia Integral de priorización y focalización 75/100 de Bogotá D.C. Política pública Distrital de Convivencia y Seguridad Ciudadana: Plan Integral de Convivencia y Seguridad Ciudadana PICSC 2013-2023. Bogotá: Alcaldía Mayor de Bogotá.

Goetz, J., y Lecompte, M. (1998). Etnografía y diseño cualitativo en investigación educativa. Madrid: Morata.

Hall, S. (2010). Sin garantías: trayectorias y problemáticas en estudios culturales. Bogotá: Instituto de estudios sociales y culturales Pensar, Universidad Javeriana, Instituto de Estudios Peruanos, Universidad Andina Simón Bolívar, sede Ecuador.

Ministerio de Educación Nacional (MEN). (2011). Decreto 1055 de 2011, Artículo 6. Bogotá: MEN.

Pérez-Gómez, A. (2005). La cultura escolar en la sociedad neoliberal. Madrid: Morata.
Reguillo Cruz, R. (2000). Emergencia de culturas juveniles. Estrategias del desencanto. Buenos Aires: Norma.

Sáenz Obregón, J. (2010). Gobierno de los pobres, culturas y saber pedagógico. Algunas líneas de fuerza emergentes en la configuración del dispositivo escolarizador público en Colombia. Revista Colombiana de Educación, No. 67, Bogotá: Universidad Pedagógica Nacional, pp. 201-226.

Secretaría Distrital de Salud, y Hospital de Kennedy. (2010). Diagnóstico local con participación social. Localidad de Kennedy. Bogotá: Alcaldía Mayor de Bogotá.

Willis, P. (1993). Producción cultural no es lo mismo que reproducción cultural, que no es lo mismo que reproducción social, que tampoco es lo mismo que reproducción. En Velasco, H. M., García, J. F., Díaz, A. (Eds.). Lecturas antropológicas para educadores. El ámbito de la antropología de la educación y de la etnografía escolar. Madrid: Trotta, pp. 389-429. 